changes are mainly compensatory, whilst in others they are excessive and hurtful; (4) that in the latter respects it resembles other provisional hypertrophies.

\section{GIDDINESS AND STAGGERING IN EAR DISEASE.}

\section{BY THOMAS BARR, M.D.GLAS.,}

Lecturer on Diseases of the Kar, Glasgow University; Aural Surgeon, Glasgow Western Infirmary; Surgeon, Glasgow Lar Hospital Honorary Aurist, Glasgow Sick Children's Hospital.

MÉNIÈre's classical paper on aural giddiness in the Gazette Médicale de Paris for February 9th, 1861, marked an epoch in the history of medicine. Founding his conclusions partly on the experiments of Flourens in 1828.42 , but chiefly upon very carefully observed cases, he demonstrated that a sudden attack of giddiness, with nausea and vomiting, with noises in the ear and deafness, has frequently its pathological basis in the interior of the ear. The view previously held that such an attack meant a lesion in the brain involved serious mistakes in prognosis and treatment. Paralysis, imbecility, and death itself were the gloomy prospects held out to such a patient; while blood-letting, mercurials, and vesicants were the nsual remedies employed. All this is now changed. In the light of Ménière's discovery and of subsequent investigations the patient who is the subject of such a seizure may now, in the majority of cases, be assured that the ear and not the brain is the seat and source of the mischief ; that the danger to life is very slight; that the dread of mental disease may be dismissed, and that, by simple and rational treatment, the symptoms will partially, if not entirely, disappear. It must be admitted, therefore, that the knowledge of the connection of these symptoms with the organ of hearing has been a great gain to medical science and fraught with valuable practical results. How desirable it is that every medical practitioner should be fully alive to the far-reaching influences of Ménière's discovery.

Frequency of Giddinges in Ear Diseage.

Since Ménière's discovery the profession has become gradually impressed with the importance of giddiness as a symptom of ear disease, and most practitioners now think of the ear when a case of giddiness presents itself. As a sign of ear disease it is by no means a rare phenomenon, occurring in all degrees of intensity from that of a slight and temporary lightness in the head to so violent a disturbance of the equilibrium as necessitates the lying posture. From my own experience, gained both in private and hospital practice, I am prepared to say that in a marked form it is far from being rare, while in a comparatively mild degree it is a very common concomitant of ear disease. At the Glasgow Ear Hospital a scheme is in use in which the existence of giddiness is included among the questions put to every patient of sufficient age, and the answer recorded. Examination of the scheme shows that in 1,276 consecutive cases, occurring in hospital practice, there were 73 cases, or $5 \frac{1}{2}$ per cent., of marked giddiness; while in 237 , or 18 per cent., there was slighter or occasional giddiness. In 1,025 consecutive cases, occurring in private practice, there were 63 cases, or 6 per cent., in which giddiness was a distinct and indubitable feature. In the case of hospital patients we cannot, of course, vouch for the accuracy of all the replies. Excluding slight and occasional giddiness observed in hospital practice from our calculation, these being possibly in many instances connected purely with gastric or hepatic disturbance, the proportion in the severe forms is pretty much the same in hospital as in private practice.

Considering the importance and frequency of giddiness as a symptom of ear disease, it is remarkable that it seems to have eluded such able observers as Wilde and Toynbee. Neither in Wilde's volume on Aural Surgery, published in 1853, nor in Toynbee's treatise on Diseases of the Ear, published in 1860 , do we find any definite reference to giddiness as a symptom of ear disease. In the supplement to the 1868 edition of Toynbee's work, however, written by James Hinton, there is reference to the symptoms of Ménière.
Various Forms of Giddinkgs DUf to Ear Disfask.

Ménière's discovery naturally stimulated much investigation, with the result, not only of still more widely connecting the symptom of giddiness with disease in the ear, but also at the same time of modifying some of his views. While he believed that these symptoms had always as their basis a lesion, usually hæmorrhagic, in the labyrinth or semicircular canals, further investigation and experience bave modified and enlarged this view, and it is now well known that giddiness may be associated with almost any form of ear disease. In the light of the fuller experience of recent years aural giddiness may now be conveniently described as manifesting itself in four distinct forms.

I. The typical form, or true Ménière's disease (sometimes termed apoplectiform deafness), due to the presence of exudation in the labyrinth. In a person with either previously normal hearing, or who may have suffered from a chronic affection of the middle ear, the four great symptomsnamely, sickness and vomiting, giddiness and staggering, subjective sounds in the ear and deafness-occur as a sudden seizure. In this class entire disappearance of all the symptoms is rare.

II. This form of aural giddiness is due to pressure upon the walls of the middle ear of air, liquid, or inflammatory products. Here the symptoms are somewhat less severe in character, the sickness and vomiting being occasionally absent. The vertigo is usually preceded by other symptoms of anditory disturbance. Disappearance of the symptoms, however, is usually effected by suitable treatment.

III. The giddiness is in this class due to pressure upon the walls of the external auditory canal or outer surface of the tympanic membrane, especially by ceruminous masses. Here, also, the giddiness is usually preceded by disturbance of the hearing, and here also entire recovery is often brought about by treatment.

IV. In the fourth class of cases, the giddiness is due to irritation of the auditory nerve, chiefly through chronic processes in the middle ear leading to pressure upon the labyrinth at the fenestral openings, or to vasomotor disturbance in the labyrinth. The vertigo of this class is that usually termed by writers vertigo ab aure lasa, and may occur in almost any affection of the ear, but usually in the course of a chronic inflammatory affection of the middle ear. The giddiness is generally preceded, accompanied, and followed by subjective sounds and deafness, but it is frequently without nauses or vomiting. Recurrences of the giddiness are common from time to time. In most cases the giddiness eventually disappears, but the deafness and noises in the ear remain permanent.

\section{I.-Labrrinthine Giddiness.}

This is true Ménière's disease or apoplectiform deafness, and is a form of aural giddiness, which is most apt to be confounded with cerebral or cerebellar disease. It is perhaps best illustrated by the description of an actual case, such as the following:

CASE I. Typical Ménière'8 Disease.-A married lady, aged 32, was never, up till the time of seizure, conscious of any impairment of hearing or affection of the ear. On a spring forenoon, while walking in the garden she became suddenly conscious of a loud sound in the left ear and left side of head, like steam blowing off, accompanied by deafness in the same ear. Almost immediately aiterwards she became extremely giddy staggering with difficulty into the house, where she became very sic and romited freely. After resting in the dining room for two or three hours she was helped up stairs to bed, still extremely giddy. Next morning, however, the vertigo had, to a great extent, disappeared, and, with the exception of slight transient attacks, has never returned. The

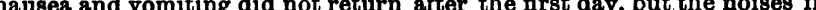
the ear and deafness continued. A few days after the attack I examined both ears. In the left, or affected, side there was no sign of disease in the external or middle ear. The hearing by air conduction was practically gone while bone conduction, as tested by Rinne's and Weber's test was very defective. Inflation of the middle ear by Politzer's method and the catheter had no appreciable effect upon the deafness or on the sub jective sonnds. The right ear was perfectly healthy, with normal jectring seven years after the seizure the condition of the left ear was unchanged. Neither tick of watch nor speech was heard, and the bon unchanged. Neither tick of watch nor speech was heard, and the bon conduction external or midale ear. The subjective sounds still continued pretty much the same, but there had been no return of the vertigo. This patient had given birth to a child prematurely a few months previous to the attack, and a year afterwards a child-born at full time-had to be treated with antispecific remedies. The husband, some years prior to his marriage, had spectic affection, for which he was treated or a long hime. In the cas of the lady a course of pilocarpin, employed subcutaneously, as well as affection. 
Analysis of the Leading Symptoms in Trde Ménistre's Diskase.

Let us now consider the leading individual symptoms which go to make up a typical case of true Ménière's disease. The giddiness is very sudden and intense, and is usually the first symptom of the seizure. The objects around may seem to rotate, or the ground in front may seem to rise or fall, or there may be a sense of movement only in the patient's body, either that of rotation or of moving backwards or forwards. There may simply be a staggering or want of control in the legs, especially in the dusk or dark, when the movements may resemble those of a drunken man. The patient is generally apt to turn or fall in the direction of the affected ear. If attacked while walking in the street, he staggers and tries to hold on by the wall or lamp-post. If he be in bed he feels as if in a ship in a storm. After a short time, from a few minutes to several days, the giddiness passes off or markedly diminishes, but it may return again, even repeatedly, although generally more slightly. A certain degree of staggering or giddiness is specially apt to return when the patient at first resumes the upright posture. It is apt, also, to be excited by sudden movement of the head, and it is often much worse in the dark. A gentleman recently informed me that in the dark his legs collapse as if paralysed, while in the light he has no difficulty in walking. Another young gentleman says that in the dark "his legs go all ways", and he takes the whole breadth of the road, so that he avoids going out at night. He walks quite well during the day. The giddiness seems sometimes to be excited by superficial irritations, or by particular postures. A patient said that when, in combing his hair, the comb touched a particular spot on the side of his head, he dropped on the floor and felt like a "spinning top." The following is the case of a lady in whom giddiness was excited when she lay on the affected ear, and who, if she turned on that side while sleeping, immediately awoke quite sick and giddy.

CASE I1. Ménière's Disease: Giddiness Excited by Lying on the Affected Ear.-A lady, nervous and liable to headaches, 61 years of age, was seized at the end of January, 1891, just before breakfast, with giddiness, dulness, and noises like machinery in the left ear, followed in an hour by nausea and vomiting. Before the attack she had perfect hearing. I saw her first on March 31st, 1891, when the hearing on the right side was $\frac{7}{70}$, and on the left $\frac{n}{4 \pi}$, where the bone conduction was defective. She was examined by me again on April 30th, 1891, when she reported that since the last visit, a month before, she had had only one attack of giddiness, unaccompanied by nausea or vomiting, when coming out of church. In a letter to me in April, 1893, she writes: "I daresay you would not be astonished to hear that I was still quite deaf in mp left ear. I do not suffer so much now from giddiness as I did at first, if my stomach is out thing moving round and round, but the feeling as if I were sailing in a storm, everything moving up and down-a most unpleasant in a storm, everything moving up and down-a most unpleasant asleep, I unconsciously turn to that side, I immediately awake quite sick and giddy: perlops I to that side, I immediately awake quite feeling; but I think I would get sick if I persevered. I cannot do with any public speaker speaking loudly or rather bawling; it makes me wilh any public speaker speaking loudly or rather bawling; it makes me hours. I know ready to jump, and the effect does not pass off for some cerned, and that may probably intensify all these feelings. I have always more or less noise, sometimes a buzzing sound, but, strange to say, this more or less noise, sometimes a buzzing sound, but, strange to say, this wush. Indeed. I could not describe it better than by saying it is the sound of water in the distance rnnning gently but accompanied by the hush of water, or, rather, more water at a great distance."

In the great majority of cases the giddiness sooner or later passes permanently away.

The sickness and vomiting usually begin soon after the disturbance of equilibrium, and are probably due to reflex action through the vagus nerve. This symptom naturally suggests the possibility of brain mischief. On the other hand, owing to this symptom. both patients and practitioners frequently regard such attacks as purely bilious in their nature. The sickness and vomiting soon pass off, and rarely extend beyond a day or two.

The suhjective sounds in the ear are always well-marked, and in many cases they are most distressing features of the disease. They generally come on simultaneously with the vertigo, but sometimes they are not experienced for a few hours after, or in rare cases for a day or two. The characters of these sounds are variously described by the patients; the following taken from my notebook are some examples:Sound of a shell, waves, railway whistls, bell, rushing, buzzing. loose shutters in wind, singing, humming, ticking, roaring, rushing water and waving of trees, whistling, sound of factory, twittering and whistling of birds and crickets, blowing off steam, howling, hissing, flaring of gas, piano playing, electric bell. The behaviour of these sounds is sometimes peculiar. For example, in the case of the electric bell, a sound precisely like an electric bell was heard followed by half a minute or so of silence, then there again came the sound of the electric bell followed by silence, this alternation going on continuously. In nearly all $\mathrm{mr}$ cases the sounds in the ear, while varying in intensity at different times, remain permanent. I have always found them present years afterwards when I had the opportunity of examining the patient.

The loss of hearing is usually very marked, often practically total. It is sometimes found to precede for a few hours the other symptoms, but in general it comes on almost simultaneously with the giddiness. As a rule a loudlyticking watch is not heard close to the ear, neither are words whispered into the ear perceived. Bone conduction is also defective, as tested both by Weber's and Rinne's test. Objective examination usually shows nothing abnormal in either the external or the middle ear. Fortunately in the large majority of cases only one ear is affected; the disease sometimes, however, affects both ears, and then, if occurring in young children, deaf-mutism is generally the result. The deafness, like the noises in the ear, is in the great majority of cases permanent.

Pallor of the face and cold sweats, with, in some cases fainting, are often observed. Unconsciousness is rare, and, if present, is very short in duration. Headache is in some cases complained of. Depression, slowness of thought, and weakness of memory may follow for a time.

The Causes of True Ménilize's Disease.

In regard to the causation of this class of cases, there is no doubt that many occur in persons who, on careful inquiry, are found to have nasal obstruction or other forms of nasal disease, and who have had, at some past time of their lives, a catarrhal affection of the ear. I have been struck by the frequency of the association of ozæna with Menière's disease. It might be expected that a tendency to vascular disturbance of the middle ear is likely to be associated with a similar tendency in the internal ear. As exciting causes, abnormal states of the constitution or blood are the most frequent sources of the attack, and my own experience would place specific disease, either in the hereditary form or during the tertiary stage of the acquired form, among the most important of all the causes. (See Case I.) In such constitutional states the proximate cause is no doubt effusion of blood into the cavities of the labyrinth from rupture of a vessel specifically diseased. Such effasions constitute irritative lesions which act upon the auditory nerve terminals in the membranous ampullæ or utricle. The degenerative lesions of the vessels, connected with Bright's disease, are no doubt in some instances the explanation of the hæmorrhage. The following case is probably an instance of this :

CASE III. Ménière's Disease associated with Bright's Disease - An unmarried lady, aged 50, of a nervous temperament and dyspeptic, was the subject of chronic atrophic rhinitis, and liable to catarrhal attacks in the middle ear. She awoke one morning (April 25th, 1891) with a severe headache and the sense of being quite deaf in the left ear. An hour or two afterwards she was seized with great giddiness, great "buzzing" in the ear and sickness. For three days she vomited everything, and had also slight diarrhœa, and had to lie in bed for a week, the giddiness during that time being such as to forbid the erect posture. It was regarded as an "attack of the liver." I saw her about a fortnight afterwards, when disturbance of equilibrium had, to a considerable extent passed off, although it still threatened to return when extra fatigued. There was practically total deafness in left ear to bone and air conduction. The noise and deafness have continued permanent, and on June 14th, 1893 , the hearing was: in right, $\frac{40}{n}$, and in left 9 . The sound, which was a combination of buzzing and ringing, with the occasional tinkle of a bell, was distressing, and always aggravated by excitement, fatigue, or extra head and sounds in the ears. She has had two attacks of acute albuminuria, with partial unconsciousness, and since spring time (1893) has been much troubled with a feeling as if the hetd were constricted with a tight band.

Atheromatous disease of the vessels is, in elderly people, an important cause of the disease. When we consider the intimate relation between the blood supply of the labyrinth and that of the interior of the cranium, the internal auditory

1 "Nervous deafness s relatively more frequent in atrophic rhinitis," J. Mir ph, Archil f. Ohr:nleilkunde, October, 1894. 
artery being a branch of the basilar, it is easy to understand that atheroma in the cerebral arteries is likely to be associated with a like degeneration of the labyrinthine vessels. The following case is a notable instance of this.

CASE IV. Ménière's Disease followed soon after by Hæmorrhage into the Brain -A well-known Glasgow gentleman, aged 74, having normal ears and hearing, while seated in his office one forenoon, became suddenly conscious of a loud "buzzing" or "singing" in one of his ears, with deafness in the same ear. He almost immediately afterwards became exremely giddy and sick. When 1 saw him a day or two afterwards the vertigo and sickness had greatly subsided, leaving behind, however, profound deainess and mosc distracting noises in the ear. No mischief whatever was found in the external or midde ear, and 1 believed it to be due to sudden hæmorrhage into the labyrinth. The deafness and sound ing continued, and a few months afterwards he was attacked with cerebral apoplexy, and died soon afterwards. Professor Gairdner, who saw sheer apoplexy of the ordinary kind, no doubt from hæmorrhage into the sheer apoplexy of the ordinary kind, no doubt from

In young children the condition may be associated with mumps, ${ }^{2}$ acute labyrinthitis of Voltolini, cerebro-spinal meningitis, or leucocythæmia. The hæmorrhage may, on the other hand, be traumatic in origin, and due to a blow or a fall on the head. Many instances of this kind have come under my own observation. The giddiness continued in such cases for many weeks, and was especially severe when the patient assumed the upright posture. There was also total loss of hearing, with great subjective sounds, which were permanent. Examination of the external or middle ear usually yielded in such cases a negative result. Excessive exertion, especially of the respiratory organs, occasionally excites effusion into the labyrinth. I have had, for example, under my care, a young gentleman, an enthusiastic football player, who, during a keenly-contested game of football, was seized with great giddiness and excessive noise in one of the ears, which also became deaf, the latter symptoms-the noise in the ear and the deafness-remaining ever after. In another of my cases, excessive blowing with the mouth in the use of a blow-pipe for several hours seemed to be the exciting cause of the disease. The disease, on the other hand, may come on while in bed, the sensation of the bed heaving, as if in a ship in a storm, being the first indication of the seizure.

Dragnosis of Troe Ménière's Disease.

We assume the affection to be labyrinthine, if, immediately after the sudden occurrence of the typical symptoms, an examination fails to discover any affection of the middle or external ear, while, at the same time, the deafness is extreme, with defective bone conduction. With such symptoms as those described, and, in the absence of disturbance of function or paralysis in the areas supplied by the other cerebral and spinal nerves, we may safely exclude the possibility of an intracranial affection, because, if the nuclei of the auditory nerve centre in the brain were affected, some of the other nerves whose centres are in juxtaposition would certainly also be involved.

\section{MEM ORANDAi \\ MEDICAL, SURGICAL, OBSTETRICAL, THERA. PEUTICAL, PATHOLOGICAL, Etc.}

\section{TETANUS FROM A CHILBLAIN.}

THe following case may be of interest on account of such a trivial ailment as a chilblain terminating fatally: On March 18th, 1895, I was called to see J. K., aged 12 years. His mother believed that for five days he had been suffering from "influenza," and she did not think it necessary to seek medical aid, as her other children had all recovered from that disease a fortnight previously. I found the patient semi-conscious, with well-marked trismus, slight dysphagia, and both tonic and clonic spasms all cver the body. There was also opisthotonos, and so rigid were the muscles that it was impossible to put him sitting in the upright position. The temperature was $100^{\circ}$, the palse about 120, respirations very irregular, perspiration profuse. During examination I noticed, on attempting to move

\footnotetext{
2 See two cases, reported by writer, of total loss of hearing in both ears, consequent upon mumps, with observations, in the Glasgow
}

the left leg, that the spasms were greatly increased, and the patient cried out, apparently in much suffering. The leg was not swollen, nor was there any enlargement of the inguinal glands. On the upper and posterior surface of the heel there was an ulcer about as large as a threepenny piece, with a purple areola about $h$ llf an inch in diameter. The mother then informed me that he had complained of a chilblain a few days before. I could only obtain a very vague account of the early part of his illness, nor do I believe he had had influenza. The patient was able with difficulty to swallow a little milk and beef tea and I administered chloral, 10 grains, every fourth hour. When I saw him on the following morning he was moribund, and died shortly afterwards.

Dunlavin, co. Wicklow.

Harman F. Lawrenson, M.D.Dub.

\section{DEATH OF A CHILD FROM THE PRESENCE OF} VOMITED MATTER IN THE LARYNX.

ON August 6th, 1895, at about 4 P.M. I was summoned in haste to see a child who, it was feared, had died suddenly. I found the child, a little girl about 5 years of age, dead, and, to all appearance, from asphyxia. The presence of a little vomited matter on the bedclothes sufficed to confirm the suspicion, and to suggest the cause.

The history was as follows: The child's dinner consisted of ham and eggs with tea. In the interval between breakfast and dinner she had an orange and some melon, and after dinner she was provided with a second orange.

Abont 45 minutes before I was called, the child, feeling sick, was put to bed by her mother. Shortly afterwards she seemed to be asleep, and the mother went on with her scrubbing, etc., in the same apartment.

When next she looked at the child it was apparently dead. Neither noise from vomiting nor from expulsive efforts had occurred sufficient to arrest the attention of the mother, who had not in the meantime been out of the apartment. The vomited matter consisted of a bit of ham measuring roughly half an inch square, and a little orange pulp.

The authorities appearing satisfied with the opinion I had expressed, that death was due to suffocation from the presence of some vomited matter in the trachea; no formal post-mortem examination was ordered. Permission, however, was granted me by the parents to make an incision in the windpipe, which I did 24 hours after death, and found, as I suspected, firmly engaged in the rima glottidis a piece of orange pulp rolled up upon itself lengthwise, and measuring 1 inch in length, and when opened out, $\frac{1}{3}$ inch in breadth at its widest part.

Death from such a cause is very uncommon. Occasionally such cases occur in association with drunkenness, and a case is referred to in Taylor's Medical Jurisprudence, p. 418, in which an infant of one year old was suffocated from the presence of curdled milk in the trachea and bronchi. What happens in such a case is that when vomiting occurs in the horizontal position a portion of the vomited matter is readily drawn by aspiration into the trachea with resulting suffoca. tion unless sufficiently vigorous expulsive efforts are set up. What is singular in the present case is that a child of 5 years of age should have been thus suffocated without any struggle occurring or noise being produced, sufficient to arrest the attention of the mother.

Rothesay.

D. Mitchell, M.D.

\section{A NOTE ON THE METHOD OF SKIN BRIDGING IN} INGUINAL COLOTOMY.

In the British Mrdicar Jodran for April 6th, 1895, Mr. Bidwell, of the West London Hospital, describes a method of insuring free exit of fæces from the upper opening in the bowel after inguinal colotomy, and at the same time of preventing recession of the gat into the abdomen. The method consists in bringing the upper lip of the skin wound through an opening made in the meso sigmoid, and attaching it to the lower lip of the wound, by which manœuvre the bowel comes to be placed across a bridge of skin, in lieu of one of glass or rubber, as employed by some surgeons.

I can fully endorse all that Mr. Bidwell has said in praise of this proceeding. The operation is rapid, and the bowel need have no sutures inserted into it, and, if the length of the skin incision is properly calculated, nothing more than the 